\title{
Neoadjuvant chemotherapy in well-differentiated fetal adenocarcinoma: a case report
}

\author{
Sihame Lkhoyaalii ${ }^{1 *}$, Saber Boutayeb ${ }^{1}$, Nabil Ismaili ${ }^{2}$, Meriem Aitelhaj ${ }^{1}$, Fahd Ouchen ${ }^{3}$, Abdellatif Benosman ${ }^{3}$ \\ and Hassan Errihani ${ }^{1}$
}

\begin{abstract}
Background: Fetal adenocarcinoma of the lung is a rare subtype of pulmonary adenocarcinoma with a relative estimated incidence of $0.5 \%$ or fewer of all lung cancers. Because of its extreme rarity, there have been no controlled clinical trials investigating treatment regimens for fetal adenocarcinoma and, as a result, there are no guidelines for management.
\end{abstract}

Case presentation: We report a case of a well-differentiated fetal adenocarcinoma, which is a variant of pulmonary blastoma, that is a low-grade malignancy and associated with a good prognosis. A 29-year-old Moroccan man presented with a well-differentiated fetal adenocarcinoma staged T3NOMO, who received 3 cycles of neoadjuvant chemotherapy followed by surgery, with no recurrence at 2 years follow-up.

Conclusion: Fetal adenocarcinoma is a rare suptype of adenocarcinoma. Surgical resection is the treatment of choice for resectable disease. The role of chemotherapy in the neoadjuvant setting or adjuvant setting is not well defined.

Keywords: Well-differentiated fetal adenocarcinoma, Chemotherapy, Prognosis

\section{Background}

Fetal adenocarcinoma (FA) of the lung is a rare subtype of pulmonary adenocarcinoma that exhibits the same tissue architecture and cell characteristics to fetal lung tissue in microscopic examination. It was considered as a variant of blastoma but according to the latest World Health Organization (WHO) classification (2004), it is currently considered as a variant of solid adenocarcinoma with mucin production [1].

FA is a rare tumor, with a relative estimated incidence of $0.5 \%$ or fewer of all lung cancers [2-5]. Because of its extreme rarity, there have been no controlled clinical trials investigating treatment regimens for FA and, as a result, there are no guidelines for management [5].

Complete surgical resection is the treatment of choice of FA, similarly to all subtypes of non- small cell lung cancer (NSCLC) [6]. Some case reports suggest that FA is rarely sensitive to chemotherapy (CMT) or radiotherapy

\footnotetext{
* Correspondence: s.Ikhoyaali@gmail.com

${ }^{1}$ Department of Medical Oncology, National Institute of Oncology, Rabat, Morocco

Full list of author information is available at the end of the article
}

[2]. An anecdotal case report shows that chemotherapy with $\mathrm{UFT}^{\odot}$ (tegafur uracil) may be useful in FA [7].

We report a case report of FA managed by neoadjuvant CMT and surgery.

\section{Case presentation}

A 29-year-old Moroccan man without medical history, had a five pack-years smoking history and stopped smoking seven years ago. He presented with a fourmonth history of chest pain and minimal hemoptysis. The physical exam was normal. A chest X-ray (Figure 1) showed a large left well- rounded pulmonary opacity.

A chest computed tomography (CT) scan showed a tumoral lesion at the left upper lobe measuring $12.5 \times$ $8 \mathrm{~cm}$. This process was well limited, heterogeneous containing calcifications and areas of necrosis extended into the chest wall without bone lysis or lymph nodes (Figure 2A) staged T3N0.

Bone scintigraphy, cerebral and abdominal CT scan showed no evidence of distant metastasis. Trans-thoracic biopsy was performed, histopathological study of the biopsy specimen showed a numerous glands showing an endometrioid morphology, occasional squamoid morules 




Figure 1 Chest X-ray showing a large left pulmonary opacity.

and relatively clear cytoplasm, the Ki-67 was $1 \%$ (low proliferation index) and based on these histopathological findings, the diagnosis of fetal adenocarcinoma was concluded (Figure 3), then the patient received neoadjuvant CMT based on etoposide at dose of $120 \mathrm{mg} / \mathrm{m} 2$ day one to three and cisplatin at $100 \mathrm{mg} / \mathrm{m}^{2}$ on day one every three weeks. Evaluation after three cycles showed disease stabilization according to Response Evaluation Criteria In Solid Tumors (RECIST) (as immunohistochemistry was unavailable).

Thirty days after the last cycle of CMT the patient underwent a left upper lobectomy with lymphadenectomy (Figure 4). The microscopic examination of the specimen found a tumor characterized by two component lesions, the first composed with well-differentiated elements of glandular proliferation rarely isolated or grouped in clusters (polyadenoid structures), which were sometimes separated by undifferentiated beaches of cells with blastomatous differentiation showing moderate cytonuclear atypia and a high mitotic activity. The tumor resection was complete with negative lymph node. The postoperative course was without anomalies.

The patient underwent a chest CT scan assessment every 3 months during the first year and then every 6 months during the second year. At 2 years of follow-up, there is no evidence of disease recurrence (Figure 2B).

\section{Discussion}

In 1982, Kradin et al. described fetal adenocarcinoma firstly as a very rare subtype of malignant lung cancer [8]. In pulmonary blastoma, sex distribution was equal and the peak incidence was (35-40 years) of age, $80 \%$ of patients are smokers [4]. These are being commonly diagnosed at an early stage without involvement of lymph node.

At the histological level, the element of WDFA characteristically shows glandular elements with tubules composed of glycogen-rich, non ciliated cells that resemble fetal lung, tubuless and squamoid morules may be seen with clear nuclei within lumens. The immature mesenchyme and epithelium mimic the embryonic lung at $10-16$ weeks gestation $[9,10]$.

Surgical resection is the standard treatment for patients with pulmonary blastoma $[4,5]$, despite the fact that there have been reports of limited success with adjuvant radiotherapy and chemotherapy [5].

The prognosis of pulmonary blastomas is poor, although prognosis of WDFA is better than biphasic [11], particularly when resection is complete, with a mortality rate of $14 \%$ and $52 \%$ respectively [4].

Our understanding of fetal adenocarcinoma is derived from case reports and small series. Koss et al. reported 28 cases of WDFA, with long follow up of 95 months, and 5 -year survival of $81 \%$. Sato et al. reported 25 cases; the vast majorities has small size and were N0 at $88 \%$ of cases [11,12]. Van Loo et al. previously reported 9 cases of WDFA there were beyond T3 stage and underwent postoperative or radiation therapy however the benefit of this treatment was unclear [13].

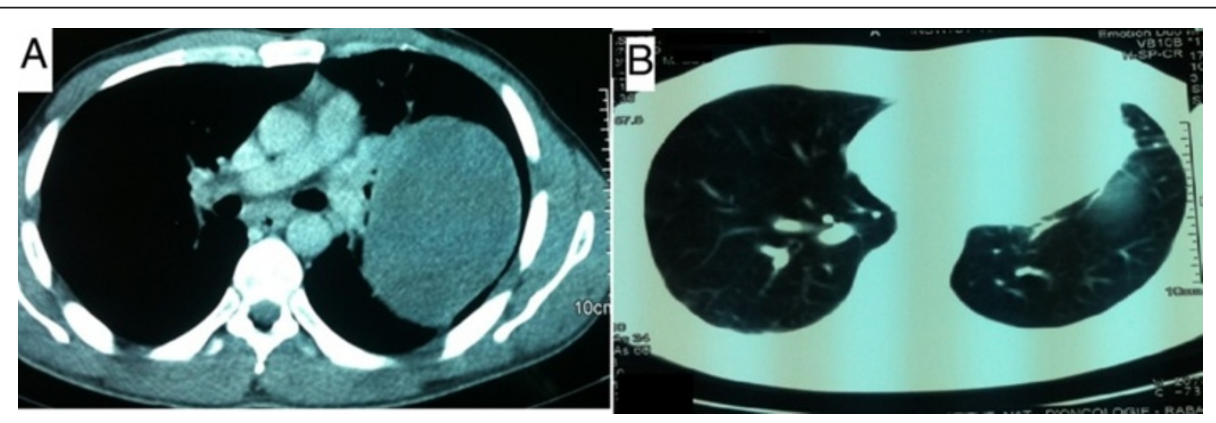

Figure $\mathbf{2}$ Chest computed tomography scan. (A): lesional process of the left upper lobe before treatment. (B): No signs of recurrence after 2 years. 


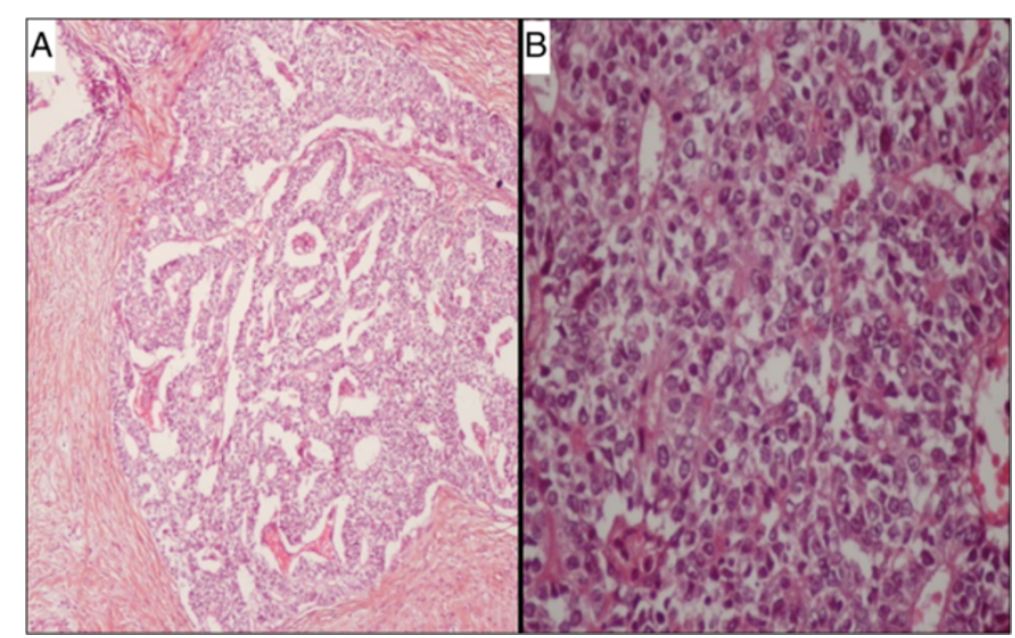

Figure 3 Microscopic examination of trans-thoracic biopsy showing a numerous glands showing an endometrioid morphology, occasional squamoid morules and relatively clear cytoplasm. (A): hematoxylin-eosin staining, original magnification $\times 10$. (B): hematoxylin-eosin staining, original magnification $\times 40$.

Our patient received 3 cycles of etoposide - cisplatin protocol. We chose this protocol because of the sensibility of fetal tumors to the combination based on etoposid and cisplatin-like nephroblastoma. Tumor response was assessed by chest CT scan after 3 cycles of CMT, and we showed $12 \%$ reduction of the tumor mass corresponding to a stable disease according to RECIST Criteria, this is due to a low proliferation of his tumor (index of proliferation, Ki-67 was 1\%).

Thus the role of neoadjuvant CMT in WDFA remains unknown, but we conclude that CMT is ineffective probably because the tumor is not proliferative, however it should be noted that Zaidi [14] has reported a case of WDFA treated with neoadjuvant CMT with mitomycin, ifosfamide and cisplatin for a WDFA staged T4NOM0 in a woman of 27 years, which successfully downstaged the tumor before surgical resection, with good control at 29 months. Also Chanhee et al. reported the first case of locally advanced WDFA treated with concurrent chemoradiation therapy with docetaxel with partial response [15]. But we have no idea of the proliferation index, and the cornerstone of treatment is surgery as much as possible.

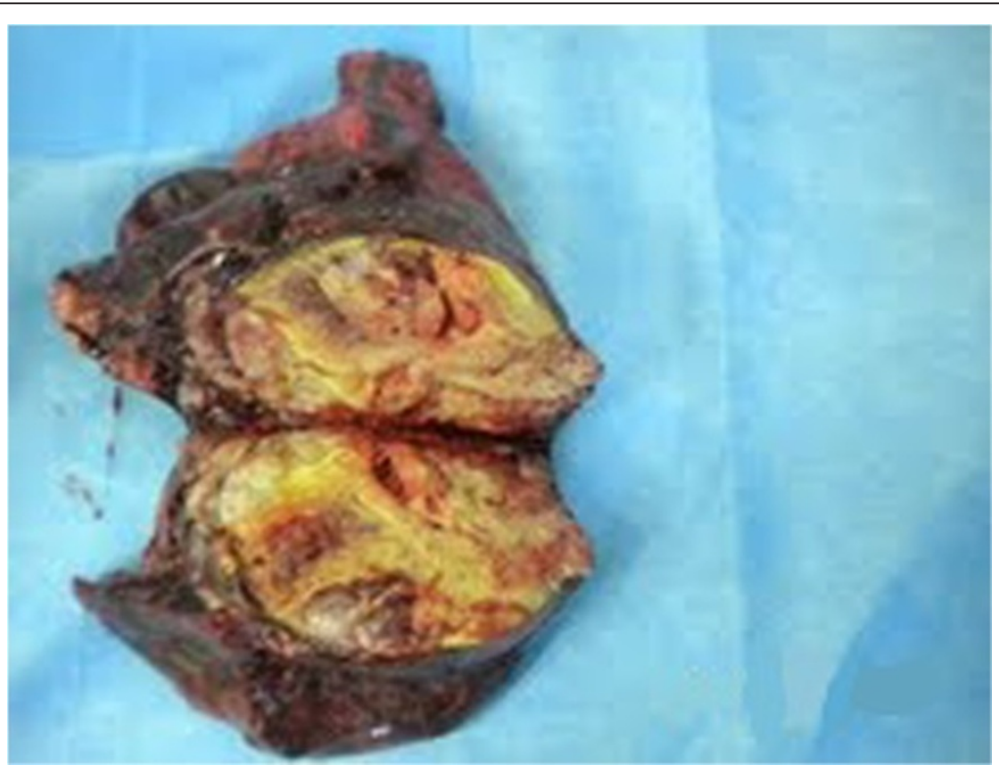

Figure 4 Macroscopic appearance of the tumor. 


\section{Conclusion}

Fetal adenocarcinoma is a rare suptype of adenocarcinoma with a better prognosis and is most commonly diagnosed at early stage with no lymph node involvement. Surgical resection is the treatment of choice for resectable disease. The role of CMT in neoadjuvant setting or adjuvant setting is not well defined.

\section{Consent}

Written informed consent was obtained from the patient for publication of this Case report and any accompanying images. A copy of the written consent is available for review by the Editor-in-Chief of this journal.

\section{Abbreviations}

FA: Fetal adenocarcinoma; WDFA: Well-differentiated fetal adenocarcinoma; WHO: World health organization; NSCLC: Non small cell lung cancer; RT: Radiotherapy; CMT: Chemotherapy; CT: Computed tomography; RECIST: Response evaluation criteria in solid tumors.

\section{Competing interests}

The authors declare that they have no competing interests.

\section{Authors' contribution}

$\mathrm{SL}$ was involved in the analysis of the data and the literature research, and she also wrote the manuscript, SB and MA helped with the literature research. $\mathrm{NI}$ helped with the patient management and revision of the manuscript. FO and BA contributed to the surgical treatment, HE approved the treatment and analyzed the literature data. All authors read and approved the final manuscript.

\section{Acknowledgments}

We would like to thank F. Kettani of pathology center (nations unies) for its cooperation and help in making the slides and the printing thereof.

\section{Author details}

${ }^{1}$ Department of Medical Oncology, National Institute of Oncology, Rabat, Morocco. ${ }^{2}$ Department of Medical Oncolgy, Marrakech, Morocco.

${ }^{3}$ Department of thoracic surgery, Hospital Avicenne, Rabat, Morocco.

Received: 15 September 2013 Accepted: 28 April 2014

Published: 5 May 2014

\section{References}

1. Travis WD, Brambilla E, Noguchi M, Nicholson AG, Geisinger KR, Yatabe $Y$ Beer DG, Powell CA, Riely GJ, Van Schil PE, Garg K, Austin JH, Asamura H, Rusch WW, Hirsch FR, Scagliotti G, Mitsudomi T, Huber RM, Ishikawa Y, Jett J, Sanchez-Cespedes M, Sculier JP, Takahashi T, Tsuboi M, Vansteenkiste J, Wistuba I, Yang PC, Aberle D, Brambilla C, Flieder D, et al: International Association for the Study of Lung Cancer/American Thoracic Society/ European Respiratory Society international multidisciplinary classification of lung adenocarcinoma. J Thorac Oncol 2011, 6:244-285.

2. Thompson RJ, Hasleton PS, Taylor PM, Woodhead M, Byrd LM: Haemoptysis in pregnancy caused by a well-differentiated fetal adenocarcinoma: a case report. J Med Case Reports 2010, 4:17.

3. Luo DL, Liu YH, Zhuang HG, Liao RQ, Luo XL, Xu FP, Zhang F: Clinicopathologic study of pulmonary adenocarcinoma with features of bronchioloalveolar carcinoma. Zhonghua Bing Li Xue Za Zhi 2008, 37(11):737-742.

4. Esper A, Force S, Gal A, Wolfenden LL: A 36-year-old woman with hemoptysis and a lung mass 3 months after delivery. Chest 2006, 130(5):1620-1623.

5. Cutler CS, Michel RP, Yassa M, Langleben A: Pulmonary blastoma: case report of a patient with a 7-year remission and review of chemotherapy experience in the world literature. Cancer 1998, 82(3):462-467.

6. Fujino S, Asada Y, Konishi T, Asakura S, Kato H, Mori A: Well-differentiated fetal adenocarcinoma of lung. Lung Cancer 1995, 13(3):311-316.
7. Matsuoka T, Sugi K, Matsuda E, Umemori Y, Okabe K, Hirasawa K, Azuma T: Clear cell adenocarcinoma with acomponent of well-differentiated fetal adenocareinoma; report of a case. Kyobu Geka 2006, 59(9):867-870.

8. Kradin RL, Young RH, GR DI C, Kirkham SE, Mark EJ: Pulmonary blastoma with agyrophil cells and lacking sarcomatous features(pulmonary endodermal tumor resembling fetal lung). Am J Surg Pathol 1982, 6:165-172.

9. Sheehan KM, Curran J, Kay EW, Broe P, Grace A: Well differentiated fetal adenocarcinoma of the lung in a 29-year-old woman. J Clin Pathol 2003, 56:478-479.

10. Politiek MJ, Vrugt B, Aalbers R: A 49-year-old woman with well differentiated fetal adenocarcinoma. The Netherlands J Med 2001, 58:177-180.

11. Koss MN, Hochholzer L, O'Leary T: Pulmonary blastomas. Cancer 1991, 67(9):2368-2381.

12. Sato S, Koike T, Yamato Y, Yoshiya K, Honma K, Tsukada H: Resected well-differentiated fetal pulmonary adenocarcnioma and summary of 25 cases reported in Japan. Jpn J Thorac Cardiovasc Surg 2006, 54:539-542.

13. Van Loo S, Boeykens E, Stappaerts I, Rutsaert R: Classic biphasic pulmonary blastoma: a case report and review of the literature. Lung Cancer 2011, 73:127-132

14. Zaidi A, Zamvar V, Macbeth F, Gibbs AR, Kulatilake N, Butchart EG: Pulmonary blastoma: medium-term results from a regional center. Ann Thorac Surg 2002, 73:1572-1575.

15. Chanhee K, Sang Y, Beom JL, Jung-Joon C, Hyung JK, Chul Min A, Heejin P, Eun NC, Yoon Soo C: A case of locally advanced well-differentiated fetal adenocarcinoma of the lung treated with concurrent chemoradiation therapy. Tuberc Respir Dis 2013, 74(5):226-223.

doi:10.1186/1756-0500-7-283

Cite this article as: Lkhoyaali et al:: Neoadjuvant chemotherapy in well-differentiated fetal adenocarcinoma: a case report. BMC Research Notes 2014 7:283.

\section{Submit your next manuscript to BioMed Central and take full advantage of:}

- Convenient online submission

- Thorough peer review

- No space constraints or color figure charges

- Immediate publication on acceptance

- Inclusion in PubMed, CAS, Scopus and Google Scholar

- Research which is freely available for redistribution 